\title{
Development of a concept for ecological city planning for St. Petersburg,
} Russia

\author{
Åsa Nystedt ${ }^{1, *}$, Mari Sepponen ${ }^{1}$ \\ ${ }^{1}$ VTT Technical Research Centre of Finland, Espoo, Suomi \\ *Corresponding author. Tel: +358 40570 3798, Fax: + 35820722 7015,E-mail asa.nystedt@vtt.fi
}

\begin{abstract}
The aim of EcoGrad, a research project conducted by VTT Technical Research Centre of Finland, was to develop a concept for the design of appropriate ecological neighborhoods for the city of St. Petersburg, Russia. A criteria list for ecological residential areas was developed together with local partners. Some differing aspects between Finnish and Russian criteria are pointed out in this paper. These are among others the attitude towards high-tech solutions, the norms regarding placement of services, and the lack of well functioning service concepts for operation and maintenance of facilities. Three pilot cases were also studied. A rough plan was made for the pilot areas including placement of buildings and services and transport solutions. Different scenarios for energy consumption and production systems were modeled and compared. Also emissions during the entire life cycle of the energy production processes were calculated with Global Emission Model for Integrated Systems (GEMIS). One of these pilot cases is described in this paper. During the project a questionnaire for residents in St. Petersburg was also made. It showed, among others, a poor willingness to pay for renewable energy and good indoor air. One of the major findings was a lack of policies and knowledge for certain renewable energy technologies and improved energy efficiency of buildings.
\end{abstract}

Keywords: City planning, Russia, Energy-efficiency

\section{Introduction}

In Russia the ecological planning is still in the early stage of development. Energy production based on renewable energy sources is also a quite unknown solution. However, there are already some regulations that support the guidelines of ecological urban planning. One of these is the regulation that orders maximum allowed distance from residences to the daily used services, such as day care centre, school, shops and health care centre.

The aim of EcoGrad, a r esearch project conducted by VTT Technical Research Centre of Finland, was to develop a concept for the design of appropriate ecological neighborhoods for the city of St. Petersburg, Russia. Local features of the areas, such us Russian regulations, social and culture facts as well as local environment and weather conditions, formed the base data for the case studies. The project started in the beginning of 2010 and lasted until the end of the year 2010. The research report of the EcoGrad project will be published in English in the publication series VTT RESEARCH NOTES [1]. The objective of this paper is to present the development process used in the project and highlight some specific differences in ecological city concepts developed for Russia compared to Finland.

As partner on the Russian side was the Coordination Center for International ScientificTechnology and Education Programmes. The most important reason for having a Russian partner was to develop the contacts to the local government. Another reason was to get help with collecting necessary basic data. In addition a student from Saint-Petersburg State University of Architecture and Civil Engineering made a one month visit to VTT in order to help with data collection. A rough examination of the Russian building norms was made.

One of the guiding principles in the planning process was Globally Optimized, Locally Designed (GOLD) principle. Practically this means that the local conditions are taken into 
consideration, when applying global optimized solutions into the EcoGrad concept. The aim was to find suitable solutions for Russia from those globally studied and applied technologies and concept solutions that are already approved to be sustainable, and suitable for ecocities.

The project included three pilot residential areas locating in St. Petersburg. A rough city plan was drawn and different energy systems were modeled and calculated. These plans included different building types in the area (residential, services and offices), floor areas of each building type, number of residents, the energy consumption level of buildings, green areas, suitable transportation solutions, and the structure of the area.

Based on the findings from the pilot studies and negotiations with the local authorities, a criteria list for an ecological city plan was made, presented, and iterated. It included aspects from the international LEED and BREEAM criteria and national Finnish criteria. The criteria list is divided into following sectors: energy, buildings, transportation, the structure of the area, land usage, landscape, waste and water solutions. There are three categories in the criteria list: general level criterion, details and specifications of the criterion and special notices from Russia. [1]

\section{Methodology}

\subsection{Progress and collecting data}

The approach was in the beginning to collect basic data and directly create plans according the EcoGrad concept for pilot areas. The general data needed was the energy efficiency level of houses being built today, ventilation systems normally used, energy prices and tariff systems, building norms, city planning process description, other relevant local regulations (such as distances to the daily services) etc. Case specific data needed was: existing transport solutions, maps of the areas, the stage of the city planning in the area, expected amount of inhabitants, etc. However, it turned out to be very difficult to get reliable base data, because it is hard to get energy consumption data on a single building level. Therefore the approach was changed. First a basic concept, based on Finnish base data, was developed. It was presented to the local authorities and adjustments were made based on the feedback received. The concept was made in more detail by adjusting it to three different pilot cases. The detailed concepts were again presented to locals and adjusted. The development process could be called an iteration process. As a result, the minimum emission saving potential in Russia could be evaluated. However, even larger emission savings may be achieved in St. Petersburg, since it is probable that the current Russian buildings consume more energy than buildings in Finland.

\subsection{Questionnaire study for residents in Russia}

Together with Finec, the St. Petersburg state university of Economics and Finance, a questionnaire for residents was made. The questions were made by VTT, and the questionnaire was performed by Finec. The questionnaire had 750 answers, 600 per email and 150 per telephone interview and face-to-face interviews. The survey was devoted to the living area conditions opinions, which included answers regarding the housing, buildings and living areas, transport etc.

The main finding was that almost all respondents (92\%) said that it is of no value for them to have their house heated with renewable energy. Less than half of the respondents $(40 \%)$ are willing to pay extra for good indoor quality, even though $80 \%$ answered that they consider good indoor quality important. Security issues could also be highlighted, $72 \%$ said that they do not feel safe in their neighborhood, which can be compared to a study made in Finland that 
showed that $81 \%$ of Finnish people living in urban areas felt really or quite safe [2]. The respondents want big apartments, over $100 \mathrm{~m} 2$, and they want to want to see parks, green areas and water when they look from their window. What also can be noted was that a rather big part, $44 \%$ of the respondents do not own a car, mainly due to economical reasons.

\subsection{Modeling of pilots}

For each pilot case, a plan of the area was done, including the structure of the area, building types and location of services as well as transportation solutions. Different energy systems were modeled and compared. At first step, the base data was collected and a plan of the area was done. Number of inhabitants, buildings and necessary service spaces were settled.

At the second step, energy consumption of the entire area was calculated in different scenarios: base case scenario, low energy building and/or passive house level. The consumption level of base case scenario was assumed to correspond to the energy consumption level of Finnish building regulations in 2008, be cause reliable sources about Russian consumption levels were not available. Consumption level of low energy and passive houses were also based on Finnish definitions [3; 4]. The energy consumption of each type building was calculated using the WinEtana program which has been developed by VTT. WinEtana calculated the consumptions of different building types from the base data: the volume of the building, number of floors, the types, areas and U-values of ceilings, windows, roof and base floor, electrical equipments and their efficiency. These values for low energy and passive building levels are expert estimations by VTT.

Different options for renewable energy production were studied. Suitable production technologies were recognized, and then emissions produced during the entire lifecycle of the energy production process were calculated using the Global Emission Model for Integrated Systems (GEMIS), which is developed by The Öko-Institut e.V. The distribution losses were also included in the calculations. Results were compared with each other. According to IEA electricity transmission losses are $10 \%$ and heat distribution losses $7 \%$ [5].

Each pilot has its own characters and special aspects. First pilot was a residential area for 20000 inhabitants. It was developed together with Pöyry Oy. The plan included different building types: one family houses, row houses and high rise buildings. The focus was on the factors affecting to the eco efficiency of the area (such as public transportation and walking and bicycling, green corridors, different building type areas, cultivation plots, placement of services and the entire area etc). This pilot has been presented shortly in this paper.

The second pilot was a residential area for 10000 inhabitants, with residential high rise buildings. It was developed with a local building company. One starting point was to develop an ecological city plan without creating any extra investment costs. Focus was therefore put mostly on non-technical solutions, and the best suitable heat energy production was district heating with woodchip boiler. The third pilot was a smaller one, including only two blocks and less than $2000 \mathrm{r}$ esident and the focus was on the development of public-private partnership business models. It locates in the coast, on the Vasili island, in central St. Petersburg. Therefore, the water heat pump solution was considered interesting, since it could also be utilised for space cooling. The electricity could be produced with building integrated solar panels as well as with small building integrated wind turbines. However, most of the electricity demand should still be bought from the national grid. As another options solar collectors were also modeled. 


\section{Results}

\subsection{The EcoGrad concept}

The EcoGrad concept was developed in the EcoGrad project. The target of the EcoGrad concept is an ecological urban planning process, which takes into account local Russian operational environment. A result of this process is to achieve an urban area, which is as eco efficient, functional and comfortable place to live, as possible. The fields included in the EcoGrad concept are: dense structure of the urban area, local environment and basis, energy efficient buildings, renewable energy production, sustainable transportation solutions, waste and water management and social facts. The aim is to utilize the concept also in the future projects in Russia.

One of the key issues of EcoGrad concept is an integrated planning process. This means that all urban planning fields are taken into consideration together already from the beginning of the planning process. In other words, the continuous co-operation of experts of different fields is really important. Then it is possible to find the solutions that are best for the entire system both environmentally and economically as well as functionally. [5]

In an energy system of the EcoGrad concept, the primary aim is to minimize the total energy consumption of the area. The main focus has to be concentrated on the energy usage of buildings as well as transportation, which are the most significant energy consumers. The energy consumption of buildings can be remarkably reduced with low energy and passive building technologies. On the other hand, the energy that is really needed in the area should be produced mainly from renewable energy sources. The optimization of the entire energy system, including heating, cooling, and electricity consumption and production, is important.

\subsubsection{Factors affecting to the implementation of projects in Russia}

The Russian building regulations can be found from the SNiP documents. The name is in Russia: СНиП - Строительные Нормы и Правила, which means Construction Rules and Regulations. SNiP is a set of regulations in the field of construction, enacted by executive state authorities, which contain obligatory requirements. SNiPs set general provisions, design requirements, rules of carrying out works and work acceptance, cost estimate guidelines. There are a large number of SNiPs, and each of them concentrates on one specific field. According to the Russian partners, the building regulations are under development process, which aim is to develop regulations toward European standards. In Russia, it is critical for all operations and projects to have knowledge about building codes and operation models.

Nowadays it is quite difficult to arrange the maintenances services of residential buildings in St. Petersburg. This is due to unclear ownership and management structures of facilities, as well as a poor level of the feature information of real estates and poor supply of services. It is unclear who should pay for the service and that often leads to the situation that the service is neglected. This needs to be considered when design includes technical aspects. This is one of the drivers that increase the interest for various Public Private Partnership business models.

Some solutions of EcoGrad concept are so multifaceted that it is necessary to have a private partner for maintaining and operating those. Without skilled private operator it cannot be assured that technical solutions operate efficient and ecologically enough, as planned. This is due to the fact that most of the solutions need special know-how and maintenance also after the construction phase. Depending on the used public private partnership model, private 
partner can also be responsible for financing, investing, designing, building, and owning of services or necessary facilities. When designing and choosing suitable business model, it is important to consider ownership, responsibilities of the various parties and financial control.

\subsection{The concept for the first pilot case}

As an example the energy system, calculations of the first pilot are briefly introduced below. The plan of the first pilot area and the volumes are presented in the Figure 1. The planned number of inhabitants in the area is 20000 . The residential area is $30 \mathrm{~m}^{2}$ per inhabitant, which means in total $600000 \mathrm{~m}^{2}$ floor area. There are five different building type areas: dense, low and dense, detached houses and villas. The inhabitation is most dense in the center of the area, which is really close to services and railway connection to the centre of St. Petersburg.
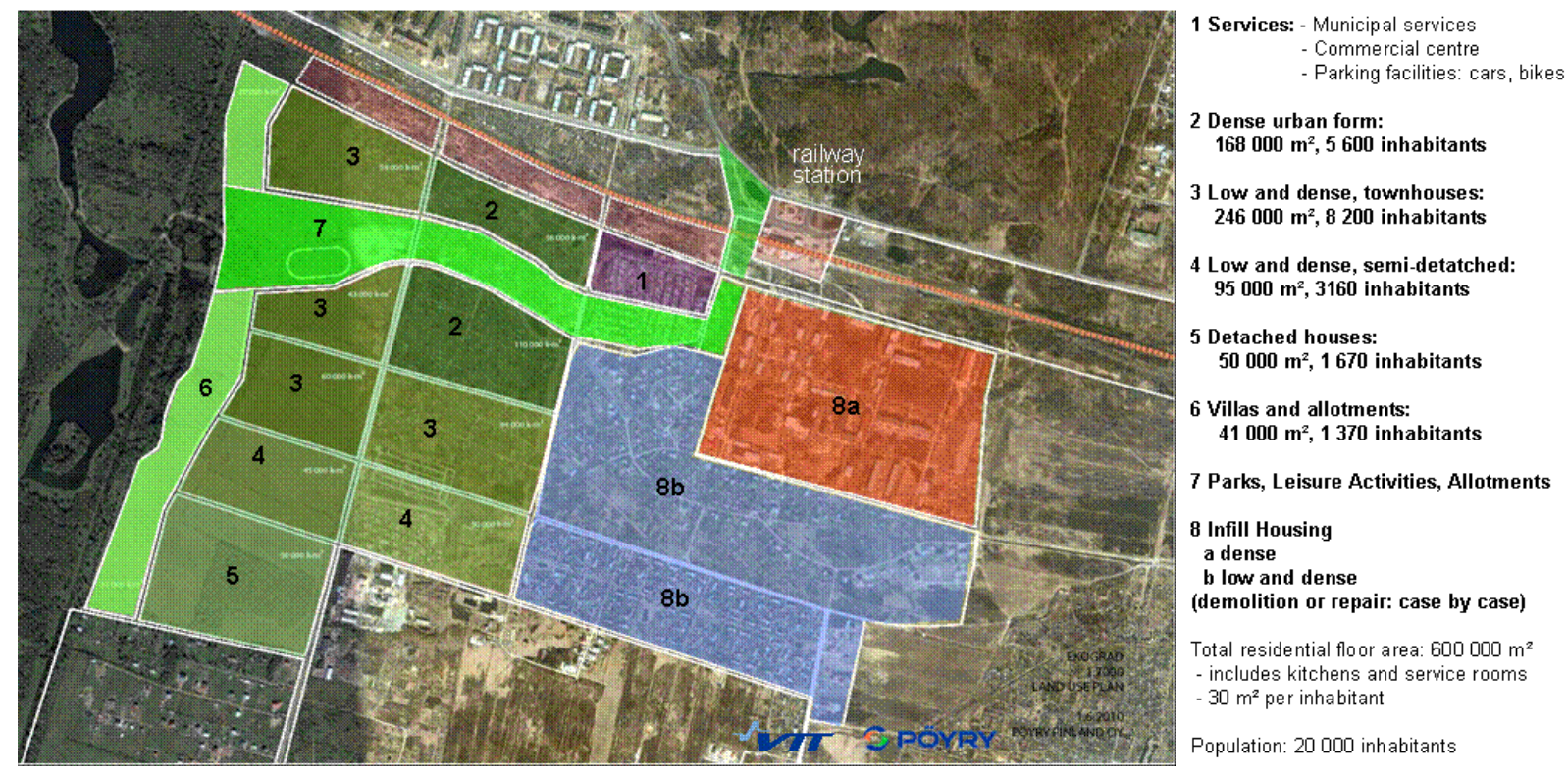

Fig. 1.Plan of the first pilot

The energy consumption has been calculated in three different scenarios: base case, low energy and passive building levels. The results can be seen from the Figure 2. M ost significant improvements are related to decreasing the heat consumption of buildings, and especially the heat consumption of space heating. It is more difficult to affect to the electricity or hot water consumption, because they depend more on the habits of the residents.

Next, different energy production options were studied. First option was quite ultimate with the target of using only renewable energy sources and achieving as low emission level as possible. That meant ground heat pumps, building integrated solar panels and wind power.

Heat collection pipes could be mounted on the golf court locating close to the pilot area. It was assumed that the COP of the heat pumps is 3 , and the heat yield is $35 \mathrm{kWh} / \mathrm{m} 2 / \mathrm{a}$. One of the challenges was the fact that heat pumps consume electricity, which is also supposed to be produced within the area. If was further assumed that the entire area of roofs could be utilized with building integrated solar panels. It was calculated that the yield of solar panels would be $17700 \mathrm{MWh} / \mathrm{a}$. This means that there should also be a lot of wind energy: in a base case $28804 \mathrm{MWh} / \mathrm{a}$ (the power capacity being 14,4 M W), low energy building level $20200 \mathrm{MWh} / \mathrm{a}$ (with the power capacity of 10,1 MW) and passive building level $17796 \mathrm{MWh} / \mathrm{a}$ (with the power capacity 8,9 MW). Power levels of wind power are calculated 
with a capacity factor $23 \%$. In this option the target was to produce as much energy as is consumed in the area, but it is assumed that the area is connected to the national electricity grid, which smoothes the differences between the production and consumption continuously.

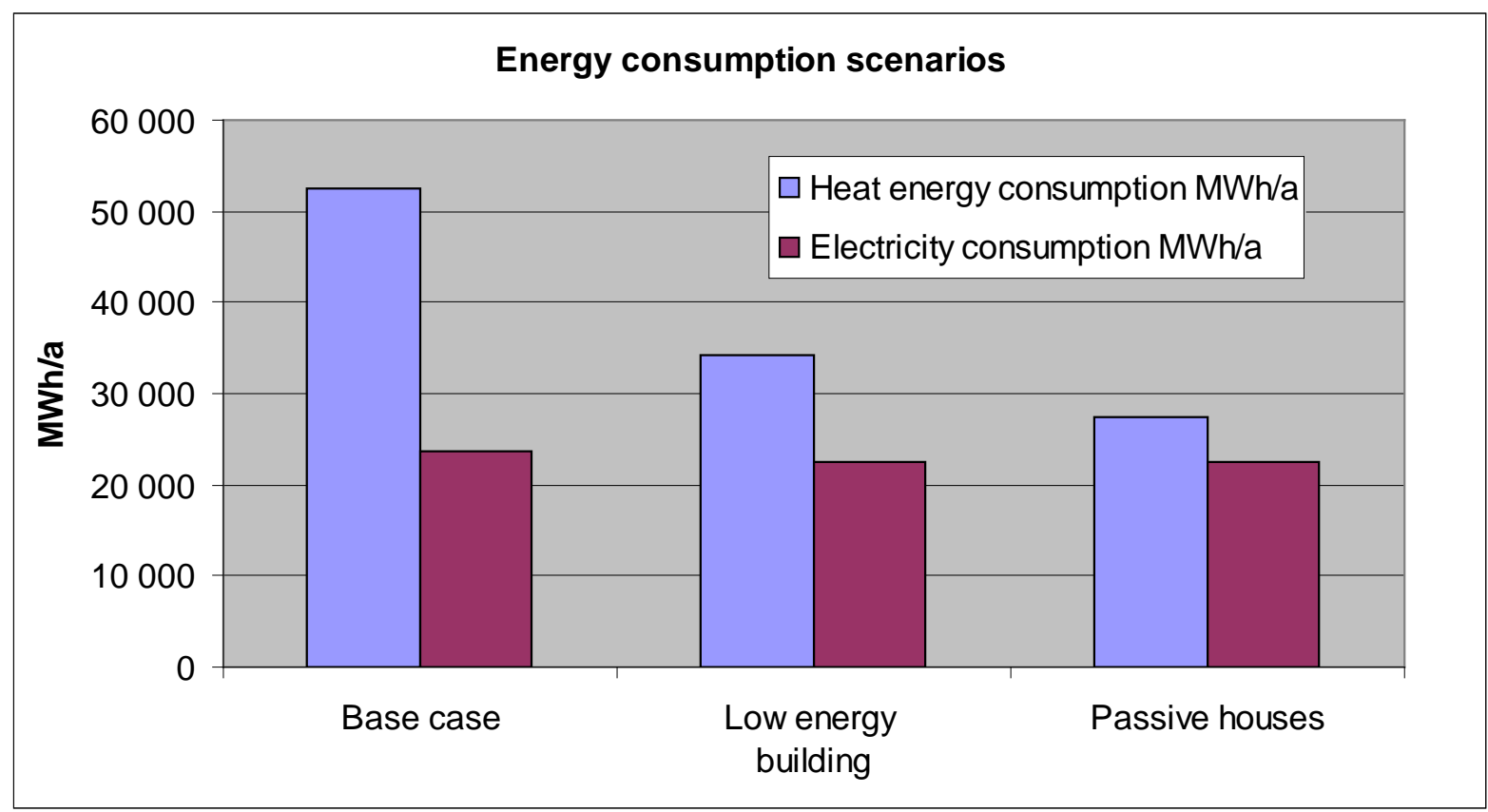

Fig. 2. Energy consumption of the pilot area in different scenarios

The second option was combined heat and power production (CHP) plant that is fuelled with woodchips. The third option was also a CHP plant, but it was fuelled with biogas produced from the wastes. It was assumed that the CHP plant is operated according to the heat demand in the area, as usual. In addition, it was assumed that the plant produces $80 \%$ of yearly heat consumption, and the rest of the heat demand is covered with reserve plants, for example natural gas boiler. The used CHP processes were calculated with the information of real existing plants from the database of the GEMIS software. The plant using wood as a fuel produced $2 \mathrm{MWh}$ of heat per $1 \mathrm{MWh}$ of electricity, with the electrical efficiency of $27,5 \%$ and operating time of $6000 \mathrm{~h} / \mathrm{a}$. The biogas CHP plant produced 1,5 MWh of heat per $1 \mathrm{MWh}$ of electricity, and the efficiency and operating time were the same as the woodchip CHP plant.

The green house gas emissions of these different energy production options are presented in Fig. 3. The emission calculations include the emissions produced during the entire life cycle of their processes (including for example construction and transportation). These results were also compared to the base case, which represents the current situation in Russia. According to IEA, in Russia buildings are heated most commonly with district heating, in which the heat is produced from natural gas. The emissions of base case electricity are calculated with GEMIS from the base data of IEA [6]. 


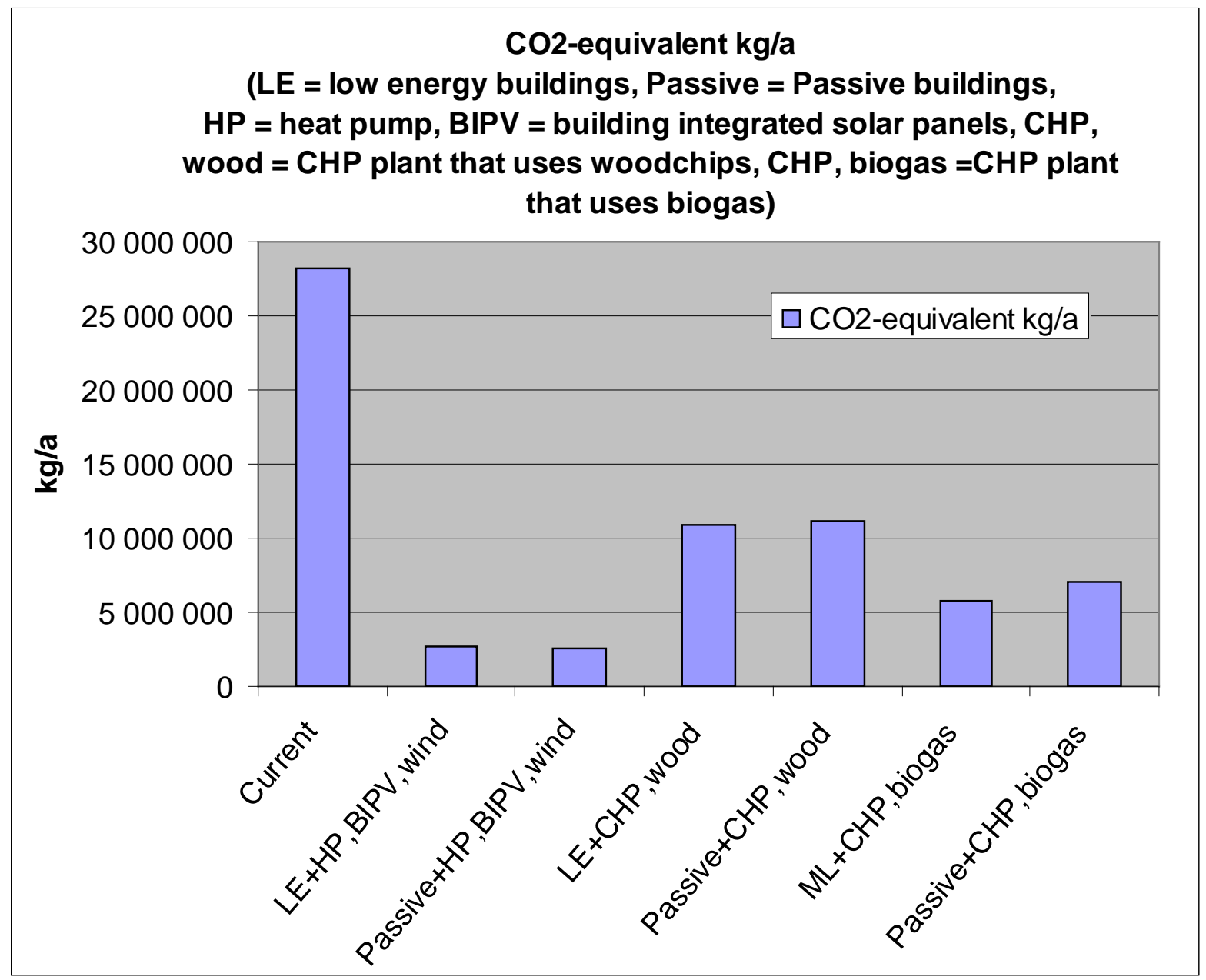

Fig. 3. Green house gas emission from different energy production options in the first pilot case. (LE = low energy buildings, Passive = Passive buildings, $\mathrm{HP}=$ heat pump, BIPV = building integrated solar panels, CHP, wood =CHP plant that uses woodchips, CHP, biogas =CHP plant that uses biogas)

\section{Conclusions}

After the whole project it can be concluded that ecological city planning principles can be applied in Russia. Ecological city plan was done for three pilot areas in St. Petersburg, and the energy consumption and production scenarios were modeled. One of the major findings was that it is important to aim buildings' energy consumption towards passive building level. Next, emissions during the entire life cycle of energy production process were calculated for each scenario with Global Emission Model for Integrated Systems (GEMIS). As a result a significant energy and emission saving potential was found. However, while modeling can be done, there are several issues that have to be considered in the planning process, and they need to be resolved before results of these modelings can be fully implemented. One of the most important further development steps is the actual implementation in these pilot areas.

It seems that there is a lack of knowledge and policies regarding renewable energy as well as technologies that improve the energy efficiency of buildings. The development of renewable energy systems is not yet common enough in Russia. Policies need to be clarified, for example the buffer zones for bio energy plants were not known by Russian partners. It was also unclear whether local legislation allows energy wells to be drilled for heat pumps. And as another example, an important part of the passive house concept is the mechanical ventilation 
with efficient heat recovery. It needs to be emphasized that buildings cannot be built airtight and well insulated unless proper ventilation is insured. However, this is quite unknown solution according to the survey for residents, and the implementation may be difficult due to local policies. Generally speaking, the issues related to base data issues, ownership and operating conditions in existing buildings have to be resolved. Future efforts should be put on exporting knowledge and best practices about these issues. With better knowledge the local norms can be developed in a sustainable way and it will also support the development of the city planning process.

Taking the criteria developed in this project into the planning process is the next step in the development of new ecological areas. In contrast to similar studies conducted in Finland, the survey results suggested that while renewable energy is not a priority for Russians in new neighborhood developments, there is an interest in indoor quality and larger living spaces. Revealed challenges include the unwillingness to pay for improvements and low safety in neighborhoods, suggesting underlying economic and social issues that need to be addressed in addition to providing energy and environmental opportunities. Generally speaking, it seems that passive solutions that are not very technology dependent are valued higher in Russia. Technological solutions are not considered ecological. Smart metering systems for electricity consumption raised interest, but were still considered with skepticism.

During the project it was noticed that it is very important to have an active local partner in this type of development project. The local partners need to have their own funding for the project to ensure that the work is being prioritized. In addition, the results of the questionnaire made for residents in St. Petersburg imply that residents should be more involved in the planning process. This is another possible future implementation of the EcoGrad project.

\section{References}

[1] Nystedt Åsa, Sepponen Mari, Virtanen Mikko, Lahti Pekka, Nummelin Johanna, Teerimo Seppo. EcoGrad - Development of a concept for ecological city planning for St. Petersburg, Russia. VTT Reseach Notes.

[2] P. Suominen, Suomi - Euroopan turvallisin maa?. Reseach report. Poliisin ylijohdon julkaisusarja 7/2009, ISBN 978-952-491-434-5. Referred 12.12.2010. http://www.poliisi.fi/intermin/biblio.nsf/3D6379853B32E72DC225768C003279F0/\$file/ 7-2009.pdf

[3] I. Strom, L. Joosten, Boonstra, J. Nieminen, M. Saari, E. Nykänen, Työraportti 1.2 Passiivisen talon ratkaisut. Work report of Promotion of European Passive Houses project. 2006. Referred 10.12.2010. Available: http://erg.ucd.ie/pep/pdf/Passive_House_Sol_Finnish.pdf

[4] J. Nieminen and K. Lylykangas, Passiivitalon määritelmä. Ohjeita passiivitalon arkkitehtisuunnitteluun. $2009 . \quad$ Referred 10.12.2010. Available: http://www.passiivi.info/download/passiivitalon maaritelma.pdf

[5] Sepponen, Mari: Technologies and solutions for the energy system of an ecocity. Master's thesis 2010, Aalto University of Technology.

[6] IEA, Electricity/Heat in Russia Federation in 2008. R eferred 2.9.2010. Available: http://www.iea.org/stats/electricitydata.asp?COUNTRY_CODE=RU 